\title{
ИМмУнология
}

\author{
УДК 612.086
}

DOI: 10.17072/1994-9952-2019-3-353-358.

\author{
Е. В. Сайдакова, В. В. Власова
}

Пермский государственный национальный исследовательский университет, Пермь, Россия

ЭКСПРЕССИЯ АКТИВНОЙ ФОРМЫ КАСПАЗЫ-З НЕ
ЯВЛЯЕТСЯ ДОСТОВЕРНЫМ ПОКАЗАТЕЛЕМ ИНДУЦИИ
АПОПТОЗА В СТИМУ ЛИРОВАННЫХ СD4
Т-ЛИМФОЦИТАХ

Цель настоящей работы - анализ экспрессии активной формы каспазы-3 в стимулированных CD4 Т-лимфоцитах и сопоставление ее с другими широко используемыми маркерами апоптоза и активности $\mathrm{CD} 4^{+}$Т-клеток. В процессе исследований мононуклеарные клетки периферической крови человека стимулировали анти-CD3/анти-CD28 антителами в течение 48 ч. и определяли экспрессию активной формы каспазы-3, маркеров активации (CD25), пролиферации (Ki-67) и апоптоза (POPRO/PI и AnnexinV/PI) методом проточной цитометрии. Было установлено, что под влиянием стимулятора доля каспаза-3-позитивных лимфоцитов среди $\mathrm{CD}^{+} \mathrm{CD} 45 \mathrm{RA}^{-}$Т-клеток увеличилась в 5.7 раз (P $<0.001)$, что не сопровождалось ростом процентного содержания умирающих клеток, определенных с использованием других маркеров апоптоза $(\mathrm{P}>0.05)$. Относительное количество клеток, экспрессирующих активную форму каспазы-3, было связано с параметрами активации $(\mathrm{R}=$ $0.878 ; \mathrm{P}<0.001)$ и пролиферации $(\mathrm{R}=0.917 ; \mathrm{P}<0.001)$, но не программируемой гибели $\mathrm{CD}^{+} \mathrm{T}-$ лимфоцитов (P > 0.05). Исходя из полученных данных можно заключить, что использование активной формы каспазы-3 в качестве единственного маркера при исследовании апоптоза стимулированных $\mathrm{CD}^{+}{ }^{+}$Т-лимфоцитов приводит к ложноположительным результатам, во многом отражающим активацию клеток. Для получения достоверных данных требуется введение дополнительных параметров, учитывающих как индукцию программируемой клеточной гибели, так и активность лимфоцитов.

Ключевые слова: $\mathrm{CD}^{+}$T-лимфоциты; апоптоз; каспаза-3; проницаемость цитоплазматической мембраны; асимметрия цитоплазматической мембраны; активация; проточная цитометрия.

E. V. Saidakova, V. V. Vlasova

Perm State University, Perm, Russian Federation

\section{EXPRESSION OF ACTIVE CASPASE-3 IS NOT A RELIABLE APOPTOSIS MARKER IN STIMULATED CD4 ${ }^{+}$T-CELLS}

\begin{abstract}
One of the common methods for flow cytometry apoptosis detection is the intracellular active caspase-3 analysis. Still, in stimulated $\mathrm{CD}^{+}{ }^{+} \mathrm{T}$-cells this molecule expression may not be a sign of the guaranteed cell death. The aim of the present work was to analyze the active caspase- 3 expression in stimulated $\mathrm{CD} 4^{+} \mathrm{T}$-lymphocytes and to compare it with other widely used apoptosis and activity markers of $\mathrm{CD} 4^{+} \mathrm{T}$ cells. We stimulated human peripheral blood mononuclear cells with anti-CD3/anti-CD28 antibodies for 48 hours and studied the expression of active caspase-3, activation (CD25), proliferation (Ki-67), and apoptosis (PO-PRO/PI and AnnexinV/PI) markers with flow cytometry. We found that under stimulation, the proportion of caspase-3-positive lymphocytes among $\mathrm{CD}^{+} \mathrm{CD}_{45 \mathrm{RA}}{ }^{-} \mathrm{T}$-cells increased by 5.7 times $(\mathrm{P}<0.001)$, which was not accompanied by an increase in the percentage of dying cells determined using other markers of apoptosis $(\mathrm{P}>0.05)$. The relative number of cells expressing active caspase- 3 was associated with activation $(\mathrm{R}=0.878 ; \mathrm{P}<0.001)$ and proliferation $(\mathrm{R}=0.917 ; \mathrm{P}<0.001)$, but not programmed death of T-lymphocytes $(\mathrm{P}>0.05)$. Based on the data obtained, we conclude that the use of active caspase3 as the only marker to study apoptosis of stimulated $\mathrm{CD}^{+}$T-lymphocytes leads to false-positive results that mainly reflect cell activation. Reliable data requires the introduction of additional parameters that take into account both the induction of programmed cell death and lymphocyte activity.
\end{abstract}

Key words: $\mathrm{CD}^{+}$T-lymphocytes; apoptosis; caspase-3; membrane permeability; membrane asymmetry; activation; flow cytometry.

Апоптотическая гибель клеток играет важную роль в поддержании гомеостаза организма [Vaux, Strasser, 1996]. Патологическое усиление или ослабление процесса программируемой клеточной смерти ассоциировано с развитием дегенеративных расстройств, аутоиммунных нарушений и он-

(C) Сайдакова Е. В., Власова В. В., 2019 
кологических заболеваний [Carson, Ribeiro, 1993; O'Reilly, Strasser, 1999; Lowe, Lin, 2000]. Важная роль в регуляции апоптоза принадлежит ферменту «каспаза-3», который расщепляет ядерную ламину, зоны фокальных и межклеточных контактов, участвует во фрагментации ДНК [Brancolini et al., 1997; Janicke et al., 1998; Kook et al., 2003]. Появление в клетке активной формы каспазы-3 принято считать «точкой невозврата» в индукции апоптоза [Fan et al., 2017]. Эта молекула используется как маркер для определения умирающих клеток в работах, направленных на изучение лейкемии, радиочувствительности, безопасности медицинских процедур и т.д. [Belloc et al., 2000; Carracedo et al., 2002; Santos et al., 2017]. Однако вопрос о том, является ли экспрессия активной формы каспазы-3 предвестником верной гибели стимулированных CD4 ${ }^{+}$Т-лимфоцитов, остается открытым.

Цель настоящей работы - проанализировать экспрессию активной формы касазы-3 в стимулированных $\mathrm{CD}^{+}$Т-лимфоцитах и сопоставить ее с другими широко используемыми маркерами апоптоза и активности $\mathrm{CD}^{+}{ }^{+}$-клеток.

\section{Материалы и методы исследований}

\section{Получение биологического материала}

План работы был утвержден локальным этическим комитетом Пермского краевого центра по профилактике и борьбе со СПИД и инфекционными заболеваниями. Каждый участник исследования подписал информированное согласие.

Забор крови осуществляли натощак из локтевой вены в пробирки, содержащие этилендиаминтетрауксусную кислоту. Мононуклеарные клетки периферической крови изолировали путем центрифугирования (400 g, 40 мин.) в градиенте плотности Диаколла $\rho=1.077$ (Диа-М, Россия). Полученные образцы подвергали контролируемому замораживанию до $-80^{\circ} \mathrm{C}$ в течение суток в среде, содержащей 90\% инактивированной теплом эмбриональной телячьей сыворотки (Gibco, США) и 10\% диметилсульфоксида (MP Biochemicals, США), после чего клетки переносили в жидкий азот для длительного хранения.

\section{Постановка культур}

Мононуклеарные клетки периферической крови размораживали и использовали для постановки культур. В образец клеток в соотношении 2:1 вносили анти-CD3 и анти-CD28 антитела, конъюгированные с магнитными бусами (Gibco, США). В качестве контроля были использованы мононуклеарные клетки без добавления митогена. Образцы культивировали в иммунологических 96-луночных круглодонных планшетах (МиниМед, Россия) в полной питательной среде при $+37^{\circ} \mathrm{C}$ в течение 48 ч.

\section{Цитометрический анализ}

Разделение мононуклеарных клеток периферической крови на субпопуляции выполняли с помощью коммерческих антител к поверхностным антигенам CD4 и CD45RA (BioLegend, CША). Тлимфоциты с фенотипом CD4 ${ }^{+} \mathrm{CD} 45 \mathrm{RA}^{-}$оценивали в качестве клеток памяти [Akbar et al., 1988].

При исследовании апоптоза Т-лимфоцитов выявляли ряд параметров:

1) активацию сигнальных путей апоптоза устанавливали по связыванию моноклональных антител, специфичных к активной форме каспазы-3 (BD Bioscience, США);

2) проницаемость клеточной мембраны детектировали, окрашивая клетки PO-PRO (Thermo Fisher Scientific, США) и йодистым пропидием (Thermo Fisher Scientific, США);

3) нарушение асимметрии клеточной мембраны исследовали, добавляя к лимфоцитам AnnexinV, конъюгированный с флуоресцентным красителем (Beckman Coulter, США).

В качестве умирающих путем апоптоза рассматривали клетки с фенотипами: Caspase-3+ $3^{+}$PO$\mathrm{PRO}^{+} \mathrm{PI}^{+}$или Annexin $\mathrm{V}^{+} \mathrm{PI}^{+}$. Делящиеся клетки оценивали при помощи анти-Ki-67 антител (BD Pharmingen, США). Активированные Тлимфоциты определяли по связыванию анти-CD25 антител (BioLegend, США). Также к активированным причисляли клетки с фенотипами $\mathrm{PO}-\mathrm{PRO}^{+} \mathrm{PI}^{-}$ или Annexin $\mathrm{V}^{+} \mathrm{PI}^{-}$.

Цитометрический анализ проводили на приборе CytoFLEX S (Beckman Coulter, США). Для визуализации и обработки результатов использовали программу CytExpert (Beckman Coulter, США).

\section{Статистическая обработка данных}

Статистическая обработка результатов выполнялась методами непараметрического анализа. Рассчитывали медиану и интерквартильный размах (25-75\%). Сравнение величин проводили с использованием U-критерия Манна-Уитни. Корреляционный анализ выполняли по методу Спирмена. Вычисления и построение графиков проводили с использованием пакета компьютерных программ Stata 11.1.

\section{Результаты и их обсуждение}

В исследование были включены 10 относительно здоровых добровольных доноров крови; в основном женщины (70\%). Средний возраст обследованных составил 33.6 года.

Двое суток инкубации мононуклеарных клеток со стимулирующим агентом привели к увеличению доли $\mathrm{CD}^{+} \mathrm{CD}^{2} 5 \mathrm{RA}^{-}$T-лимфоцитов, экспрессирующих активную форму каспазы-3 (рис. 1). 


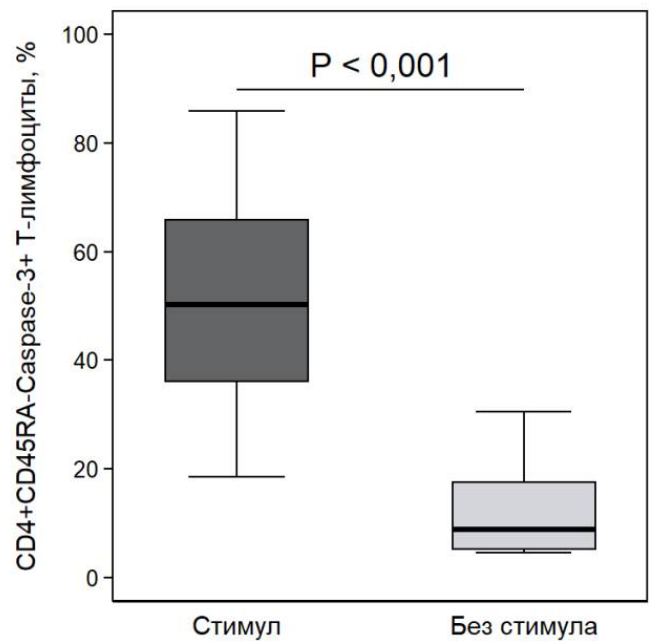

Рис. 1. Процентное содержание каспаза-3 клеток.

Мононуклеарные клетки выделяли из перифериической крови здоровых людей $(\mathrm{n}=10)$ и инкубировали 48 ч. с добавлением анти-CD3/анти-CD28 антител (стимул) или без них (без стимула). Различия между группами устанавливали с использованием U-критерия Манна-Уитни

Параллельно с анализом экспрессии активной формы каспазы-3 нами были определены другие маркеры апоптоза $\mathrm{CD}^{+}$T-лимфоцитов: увеличение проницаемости и нарушение асимметрии клеточной мембраны. При их использовании было установлено, что 48 ч. инкубации со стимулирующим агентом не приводят к увеличению количества $\mathrm{CD}^{+}$T-клеток памяти, умирающих путем апоптоза (таблица).

Относительное количествоCD4 ${ }^{+}$T-клеток памяти, умирающих путем апоптоза

\begin{tabular}{c|c|c}
\hline Показатели & Стимул & Без стимула \\
\hline \hline PO-PRO $^{+} \mathrm{PI}^{+}, \%$ & 9.0 & 6.4 \\
& $(1.3-24.8)$ & $(2.1-11.7)$ \\
\hline Annexin ${ }^{+} \mathrm{PI}^{+}, \%$ & 20.6 & 8.7 \\
& $(6.7-24.4)$ & $(3.6-21.8)$ \\
\hline
\end{tabular}

Примечание. Указаны медианы и интерквартильные размахи. Мононуклеарные клетки выделяли из периферической крови здоровых людей и инкубировали 48 ч. с добавлением анти-CD3/анти-CD28 антител (стимул) или без них (без стимула). Лимфоциты с фенотипом $\mathrm{CD} 4{ }^{+} \mathrm{CD} 45 \mathrm{RA}^{-}$окрашивали наборами красителей, отражающих индукцию апоптоза. Статистический анализ $\mathrm{U}$-критерий Манна-Уитни.

Корреляционный анализ продемонстрировал отсутствие статистически значимых связей между процентным содержанием $\mathrm{CD}^{+} \mathrm{CD}^{2} 5 \mathrm{RA}^{-}$Caspase$3^{+}$и $\mathrm{CD}^{+} \mathrm{CD} 45 \mathrm{RA}^{-} \mathrm{PO}-\mathrm{PRO}^{+} \mathrm{PI}^{+}$Т-клеток ( $\mathrm{P}>$ 0.05). Корреляции между относительными количе-

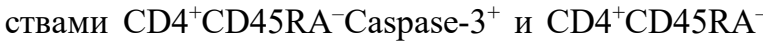
Annexin $\mathrm{V}^{+} \mathrm{PI}^{+}$T-лимфоцитов также выявлено не было (P > 0.05). Вместе с тем, доли умирающих клеток, определенные при помощи красителей, от- ражающих увеличенную проницаемость и нарушенную асимметрию клеточной мембраны, были статистически значимо связаны между собой (рис. 2).

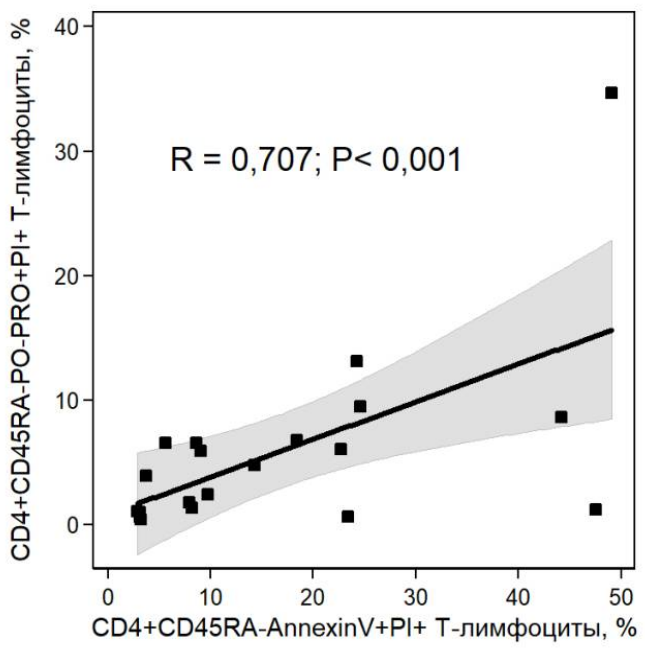

Рис. 2. Различные подходы к определению апоптоза дают схожие результаты.

$\mathrm{R}$ - коэффициент ранговой корреляции Спирмена

В отсутствие связей с показателями апоптоза, экспрессия каспазы-3 оказалась ассоциирована с индексами активности стимулированных $\mathrm{CD}^{+} \mathrm{T}$ клеток. Так, процентное содержание Т-клеток памяти, несущих активную форму каспазы-3, коррелировало с долей активированных $\left(\mathrm{CD} 25^{+}\right) \mathrm{T}$ лимфоцитов (рис. 3). Важно отметить, что другие показатели апоптоза не имели статистически значимых корреляционных зависимостей с содержанием $\mathrm{CD} 4^{+} \mathrm{CD} 25^{+}$Т-клеток памяти.

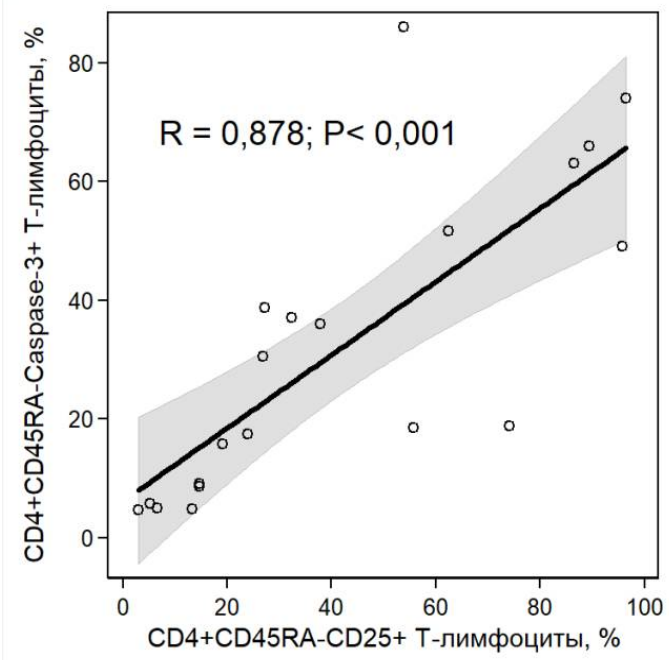

Рис. 3. Связь процентного содержания каспаза-

$3^{+}$и активированных CD4 ${ }^{+}$Т-клеток памяти.

$\mathrm{R}$ - коэффициент ранговой корреляции Спирмена

Также относительное количество каспаза-3поззитивных $\mathrm{CD}^{+}$T-клеток памяти было статистически значимо связано с долей делящихся (Ki$67^{+} \mathrm{CD}^{+}$Т-лимфоцитов (рис. 4). При использова- 
нии других маркеров программируемой гибели клеток схожих корреляционных зависимостей обнаружено не было (P > 0.05).

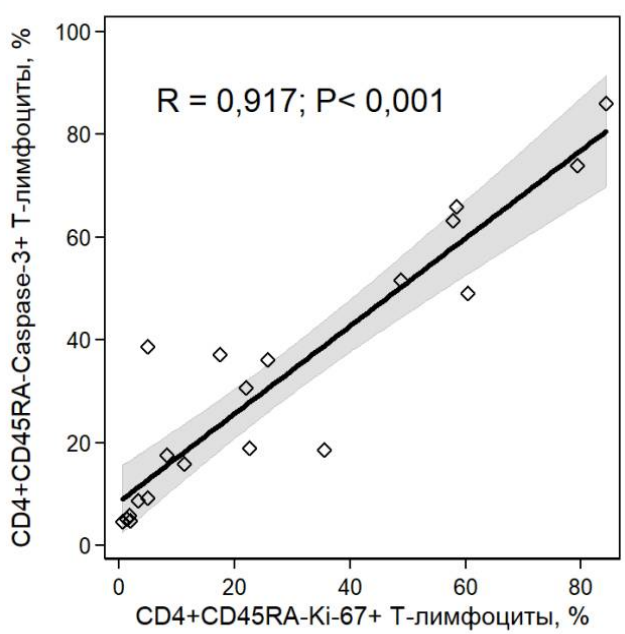

Рис. 4. Связь экспрессии активной формы каспазы-3 и пролиферации $\mathrm{CD}^{+}{ }^{\mathrm{T}}$-клеток памяти.

$\mathrm{R}$ - коэффициент ранговой корреляции Спирмена

В свою очередь, число каспаза-3-содержащих Т-клеток памяти было ассоциировано с долей $\mathrm{CD}^{+}{ }^{+} \mathrm{CD} 45 \mathrm{RA}^{-}$Annexin ${ }^{+} \mathrm{PI}^{-}$Т-клеток (рис. 5) и процентным содержанием $\mathrm{CD}^{+} \mathrm{CD}^{2} 5 \mathrm{RA}^{-} \mathrm{PO}-$ $\mathrm{PRO}^{+} \mathrm{PI}^{-} \mathrm{T}$-лимфоцитов (рис. 6). Важно отметить, что относительное количество активированных $\left(\mathrm{CD} 25^{+}\right)$Т-клеток памяти также было статистически значимо связано как с долей $\mathrm{PO}^{-\mathrm{PRO}^{+} \mathrm{PI}^{-} \mathrm{T}-}$ лимфоцитов $(\mathrm{R}=0.684 ; \mathrm{P}<0.001)$, так и с процентным содержанием Annexin $\mathrm{V}^{+} \mathrm{PI}^{-} \mathrm{T}$-клеток $(\mathrm{R}=$ 0.893; $\mathrm{P}<0.001)$.

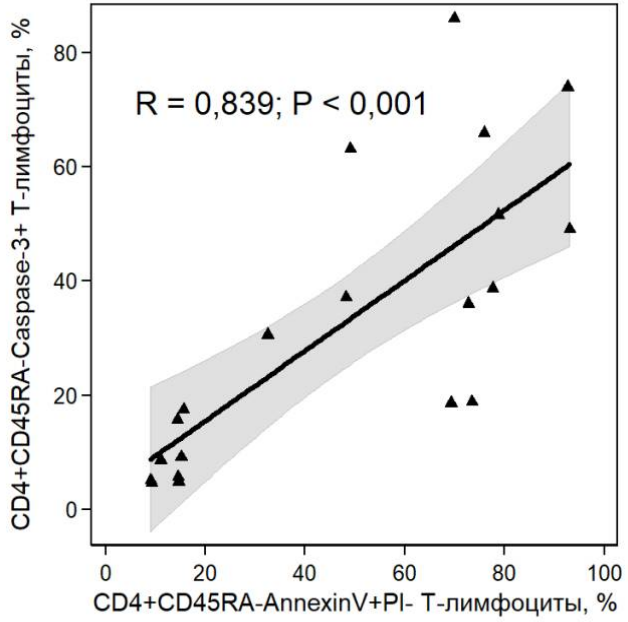

Рис. 5. Связь экспрессии активной формы каспазы-3 и нарушения асимметрии мембраны жизнеспособных $\mathrm{CD}^{+}{ }^{+}$T-клеток памяти.

$\mathrm{R}$ - коэффициент ранговой корреляции Спирмена

Таким образом, в результате проведенных исследований нами было установлено, что при стимуляции клеток через Т-клеточный рецептор в жизнеспособных $\mathrm{CD}^{+}$T-лимфоцитах памяти пе- риферической крови человека индуцируется экспрессия активной формы каспазы-3. Число каспаза-3-позитивных $\mathrm{CD}^{+} \mathrm{CD}^{4} 5 \mathrm{RA}^{-}$T-клеток ассоциировано с показателями активации $\left(\mathrm{CD} 25^{+}\right.$, $\mathrm{PO}-$ $\mathrm{PRO}^{+} \mathrm{PI}^{-}, \mathrm{AnnexinV}^{+} \mathrm{PI}^{-}$) и пролиферации $\left(\mathrm{Ki}-67^{+}\right)$ Т-лимфоцитов, но не коррелирует с показателями апоптоза $\left(\mathrm{PO} \mathrm{PRO}^{+} \mathrm{PI}^{+}, \mathrm{AnnexinV}^{+} \mathrm{PI}^{+}\right.$) этих клеток.

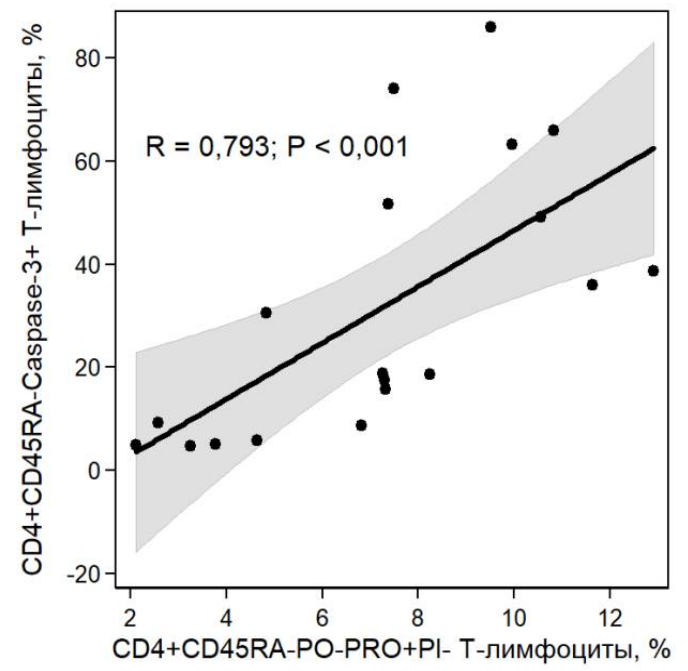

Рис. 6. Связь экспрессии активной формы каспазы-3 и проницаемости мембраны жизнеспособных $\mathrm{CD}^{+}$Т-клеток памяти.

$\mathrm{R}$ - коэффициент ранговой корреляции Спирмена

Каспаза-3 относится к числу эффекторных цистеиновых протеаз. Её функции напрямую связаны с развитием характерной для апоптоза морфологии клетки [Alnemri, 1997], но не ограничиваются индукцией программируемой гибели. Так, она вовлечена в дифференцировку скелетной мускулатуры [Fernando et al., 2002], деление В-лимфоцитов [Woo et al., 2003] и созревание эритроцитов [Lamkanfi et al., 2007]. В Т-лимфоцитах каспаза-3 необходима для запуска активных фаз клеточного цикла [Alam et al., 1999; Kennedy et al., 1999], a ee ингибирование приводит к дефекту пролиферации стимулированных наивных Т-клеток [Alam et al, 1999]. Также известно, что в жизнеспособных активированных Т-клетках каспаза-3 сохраняет способность расщеплять свои физиологические субстраты (PARP, ядерная ламина), хотя в присутствие интерлейкина-2 наличие активной формы каспазы-3 не приводит к расщеплению ДНК [Wilhelm, Wagner, Hacker, 1998]. Вероятно, в сигнальном пути апоптоза существуют контрольные точки, предотвращающие гибель клетки вопреки действию каспазы-3. Механизмы регуляции активности каспазы-3 в жизнеспособных клетках на сегодняшний день остаются неизвестными.

\section{Заключение}

Согласно полученным нами данным, экспрессия активной формы каспазы-3 плотно связана с 
активацией и пролиферацией $\mathrm{CD}^{+} \mathrm{CD}^{2} 5 \mathrm{RA}^{-} \mathrm{T}$ клеток. Поэтому ее использование в качестве единственного маркера при исследовании апоптоза стимулированных $\mathrm{CD}^{+}$Т-лимфоцитов может приводить к получению ложноположительных результатов. Комбинирование с другими параметрами, отражающими индукцию программируемой клеточной гибели и активность лимфоцитов, может облегчить интерпретацию получаемых данных и увеличить достоверность выводов.

\section{Библиографический список}

Akbar A.N. et al. Loss of CD45R and gain of UCHL1 reactivity is a feature of primed $\mathrm{T}$ cells // J. Immunol. 1988. Vol. 140. P. 2171-2178.

Alam A. et al. Early activation of caspases during T lymphocyte stimulation results in selective substrate cleavage in nonapoptotic cells // J. Exp. Med. 1999. Vol. 190. P. 1879-1890.

Alnemri E.S. Mammalian cell death proteases: a family of highly conserved aspartate specific cysteine proteases // J. Cell Biochem. 1997. Vol. 64. P. 33-42.

Belloc $F$. et al. Flow cytometry detection of caspase 3 activation in preapoptotic leukemic cells // Cytometry. 2000. Vol. 40. P. 151-160.

Brancolini $C$. et al. Dismantling cell-cell contacts during apoptosis is coupled to a caspasedependent proteolytic cleavage of beta-catenin // J. Cell Biol. 1997. Vol. 139. P. 759-771.

Carracedo $J$. et al. Caspase-3-dependent pathway mediates apoptosis of human mononuclear cells induced by cellulosic haemodialysis membranes // Nephrol. Dial. Transplant. 2002. Vol. 17. P. 1971-1977.

Carson D.A., Ribeiro J.M. Apoptosis and disease // The Lancet. 1993. Vol. 341. P. 1251-1254.

Fan J. et al. Circulating Peptidome and TumorResident Proteolysis // Enzymes. 2017. Vol. 42. P. $1-25$.

Fernando $P$. et al. Caspase 3 activity is required for skeletal muscle differentiation // Proc. Natl. Acad. Sci. USA. 2002. Vol. 99. P. 11025-11030.

Janicke R.U. et al. Caspase-3 is required for DNA fragmentation and morphological changes associated with apoptosis // J. Biol. Chem. 1998. Vol. 273. P. 9357-9360.

Kennedy N.J. et al. Caspase activation is required for T cell proliferation // J. Exp. Med. 1999. Vol. 190. P. 1891-1896.

Kook $S$. et al. Caspase-dependent cleavage of tensin induces disruption of actin cytoskeleton during apoptosis // Biochemical and Biophysical Research Communications. 2003. Vol. 303. P. $37-45$.
Lamkanfi $M$. et al. Caspases in cell survival, proliferation and differentiation // Cell Death. Differ. 2007. Vol. 14. P. 44-55.

Lowe S.W., Lin A.W. Apoptosis in cancer // Carcinogenesis. 2000. Vol. 21. P. 485-495.

O'Reilly L.A., Strasser A. Apoptosis and autoimmune disease // Inflamm. Res. 1999. Vol. 48. P. 5-21.

Santos N.F.G.D. et al. Active caspase-3 expression levels as bioindicator of individual radiosensitivity // An. Acad. Bras. Cienc. 2017. Vol. 89. P. 649659.

Vaux D.L., Strasser A. The molecular biology of apoptosis // Proc. Natl. Acad. Sci. USA. 1996. Vol. 93. P. 2239-2244.

Wilhelm S., Wagner H., Hacker G. Activation of caspase-3-like enzymes in non-apoptotic T cells // Eur. J. Immunol. 1998. Vol. 28. P. 891-900.

Woo $M$. et al. Caspase- 3 regulates cell cycle in B cells: a consequence of substrate specificity // Nat. Immunol. 2003. Vol. 4. P. 1016-1022.

\section{References}

Akbar A.N., Terry L., Timms A., Beverley P.C. and Janossy G. Loss of CD45R and gain of UCHL1 reactivity is a feature of primed T cells. $J$. Immunol. V. 140 (1988): pp. 2171-2178.

Alam A., Cohen L.Y., Aouad S. and Sekaly R.P. Early activation of caspases during $\mathrm{T}$ lymphocyte stimulation results in selective substrate cleavage in nonapoptotic cells. J. Exp. Med. V. 190 (1999): pp. 1879-1890.

Alnemri E.S. Mammalian cell death proteases: a family of highly conserved aspartate specific cysteine proteases. J. Cell Biochem. V. 64 (1997): pp. 33-42.

Belloc F., Belaud-Rotureau M.A., Lavignolle V., Bascans E., Braz-Pereira E., Durrieu F. and Lacombe F. Flow cytometry detection of caspase 3 activation in preapoptotic leukemic cells. Cytometry. V. 40 (2000): pp. 151-160.

Brancolini C., Lazarevic D., Rodriguez J. and Schneider C. Dismantling cell-cell contacts during apoptosis is coupled to a caspasedependent proteolytic cleavage of beta-catenin. $J$. Cell Biol. V. 139 (1997): pp. 759-771.

Carracedo J., Ramirez R., Soriano S., Martin-Malo A., Rodriguez M. and Aljama P. Caspase-3dependent pathway mediates apoptosis of human mononuclear cells induced by cellulosic haemodialysis membranes. Nephrol. Dial. Transplant. V. 17 (2002): pp. 1971-1977.

Carson D.A. and Ribeiro J.M. Apoptosis and disease. The Lancet. V. 341 (1993): pp. 1251-1254.

Fan J., Ning B., Lyon C.J. and Hu T.Y. Circulating Peptidome and Tumor-Resident Proteolysis. Enzymes. V. 42 (2017): pp. 1-25. 
Fernando P., Kelly J.F., Balazsi K., Slack R.S. and Megeney L.A. Caspase 3 activity is required for skeletal muscle differentiation. Proc. Natl. Acad. Sci. USA. V. 99 (2002): pp. 11025-11030.

Janicke R.U., Sprengart M.L., Wati M.R. and Porter A.G. Caspase-3 is required for DNA fragmentation and morphological changes associated with apoptosis. J. Biol. Chem. V. 273 (1998): pp. 9357-9360.

Kennedy N.J., Kataoka T., Tschopp J. and Budd R.C. Caspase activation is required for $\mathrm{T}$ cell proliferation. J. Exp. Med. V. 190 (1999): pp. 1891-1896.

Kook S., Do H.K., Sang R.S., Wook K., Jang-Soo C. and Woo K.S. Caspase-dependent cleavage of tensin induces disruption of actin cytoskeleton during apoptosis. Biochemical and Biophysical Research Communications. V. 303 (2003): pp. $37-$ 45.

Lamkanfi M., Festjens N., Declercq W., Vanden Berghe T. and Vandenabeele P. Caspases in cell survival, proliferation and differentiation. Cell Death. Differ. V. 14 (2007): pp. 44-55.

\section{Об авторах}

Сайдакова Евгения Владимировна, кандидат биологических наук, доцент кафедры микробиологии и иммунологии ФГБОУВО «Пермский государственный национальный исследовательский университет» ORCID: 0000-0002-4342-5362

614990, Пермь, ул. Букирева, 15;

radimira@list.ru; (905)8611675

Власова Виолетта Викторовна, магистрант биологического факультета

ФГБОУВО «Пермский государственный национальный исследовательский университет»

ORCID: 0000-0002-1656-7277

614990, Пермь, ул. Букирева, 15;

violetbaudelaire73@gmail.com; (996)3241201
Lowe S.W. and Lin A.W. Apoptosis in cancer. Carcinogenesis. V. 21 (2000): pp. 485-495.

O'Reilly L.A. and Strasser A. Apoptosis and autoimmune disease. Inflamm. Res. V. 48 (1999): pp. $5-21$.

Santos N.F.G.D., Silva R.F., Pinto M.M.P.L., Silva E.B.D., Tasat D.R. and Amaral A. Active caspase-3 expression levels as bioindicator of individual radiosensitivity. An. Acad. Bras. Cienc. V. 89 (2017): pp. 649-659.

Vaux D.L. and Strasser A. The molecular biology of apoptosis. Proc. Natl. Acad. Sci. USA. V. 93 (1996): pp. 2239-2244.

Wilhelm S., Wagner H. and Hacker G. Activation of caspase-3-like enzymes in non-apoptotic T cells. Eur. J. Immunol. V. 28 (1998): pp. 891-900.

Woo M., Hakem R., Furlonger C., Hakem A., Duncan G.S., Sasaki T., Bouchard D., Lu L., Wu G.E., Paige C.J. and Mak T.W. Caspase-3 regulates cell cycle in B cells: a consequence of substrate specificity. Nat. Immunol. V. 4 (2003): pp. 1016-1022.

Поступила в редакцию 23.07.2019

\section{Информация для цитирования:}

Сайдакова Е.В., Власова В.В. Экспрессия активной формы каспазы-3 не является достоверным показателем индукции апоптоза в стимулированных $\mathrm{CD}^{+}$Т-лимфоцитах // Вестник Пермского университета. Cер. Биология. 2019. Вып. 3. С. 353-358. DOI: 10.17072/1994-9952-2019-3-353-358.

Saidakova E.V., Vlasova V.V. [Expression of active caspase-3 is not a reliable apoptosis marker in stimulated CD4+ T-cells]. Vestnik Permskogo universiteta. Biologija. Iss. 3 (2019): pp. 353-358. (In Russ.). DOI: 10.17072/1994-9952-2019-3-353-358. 
